
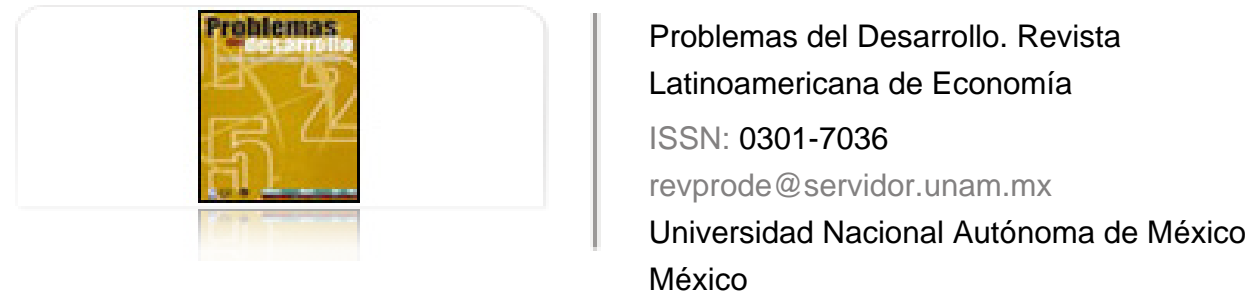

Valdivieso Canal, Susana

¿Nuevos aires en la teoría del desarrollo?

Problemas del Desarrollo. Revista Latinoamericana de Economía, vol. 37, núm. 144, enero-marzo,

2006, pp. 11-31

Universidad Nacional Autónoma de México

Distrito Federal, México

Disponible en: http://www.redalyc.org/articulo.oa?id=11820097002

Cómo citar el artículo

- Número completo

- Más información del artículo

Página de la revista en redalyc.org

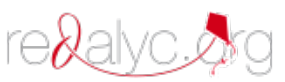

Sistema de Información Científica

Red de Revistas Científicas de América Latina, el Caribe, España y Portugal Proyecto académico sin fines de lucro, desarrollado bajo la iniciativa de acceso abierto 


\section{¿NUEVOS AIRES EN LA TEORÍA DEL DESARROLLO?}

\section{Susana Valdivieso Canal*}

Fecha de recepción: 19 de febrero de 2005. Fecha de aceptación: 4 de noviembre de 2005.

\section{Resumen}

En las últimas décadas el programa de investigación de la llamada nueva economía institucional (NEI) ha propiciado un interesante debate al interior de las ciencias sociales, el cual tiene como foco de atención los determinantes del comportamiento económico y político de las sociedades. Uno de los méritos de dicho debate es haber superado la mirada centrada únicamente en los aspectos económicos, para proponer una visión integral de los procesos sociales. El objetivo del artículo es reseñar los referentes teóricos y la interpretación del atraso en América Latina de la NEI, con el propósito de destacar sus logros y, también, algunas de sus fisuras.

Palabras clave: marco institucional, costos de transacción, derechos de propiedad, desarrollo, capital social, políticas públicas.

\section{Abstract}

In recent decades, the so-called new institutional economy (NIE) research program has led to an interesting debate in the social sciences, with a focus on the determinants of the economic and political performance of societies. One of the merits of this debate is to have gone beyond the view centered uniquely on economic aspects, by proposing an integrated vision of social processes. The aim of this paper is to review the theoretical references and the interpretation of the backwardness of NIE in Latin America, with the proposal of emphasizing its achievements and also some of its shortcomings.

Key words: institutional framework, trade cost, property rights, development, social capital, public policies.

* Profesora titular y directora de la Escuela de Economía, Universidad Industrial de Santander, Colombia. Correo electrónico: svaldiv@uis.edu.co 


\section{Résumé}

Dans les dernières décades, le programme d'investigation de la nouvelle économie institutionnelle (NEI) a encouragé un intéressant débat à l'intérieur des sciences sociales dont le centre d'intérêt sont les déterminantes du comportement économique et politique des sociétés. Un des mérites de ce débat c'est le fait d'avoir surpassé le regard centré uniquement sur les aspects économiques, pour proposer une vision intégrale des processus sociaux. Le but de l'article est de faire la liste des référents théorique et de l'interprétation du retard en Amérique Latine de la NEI, avec pour but de faire ressortir ses réussites ainsi que quelques unes de ses fissures.

Mots-cléfs: cadre institutionnel, coûts de transaction, droits de propriété, développement, capital social, politiques publiques.

\section{Resumo}

Nos últimos decénios o programa de pesquisa da denominada nova economia institucional (nei) provocou um interessante debate no interior das ciencias sociais, o qual tem como foco de atenção os determinantes do comportamento económico e político das sociedades. Um dos méritos de tal debate é ter superado a mirada centrada somente nos aspectos económicos, para propôr uma visão integral dos processos sociais. O objetivo do artigo é enumerar os referentes teóricos e a interpretação do atrasso na América Latina da nei, com o objetivo de destacar seus avanços e, também, algumas das suas falhas.

Palavras chave: marco institucional, costes de transação, dereitos de propiedade, desenvolvimento, capital social, politicas públicas.

\section{DeSarrollo}




\section{Introducción}

n las últimas décadas, con particular énfasis a partir de los años noventa, lo que se
ha concebido como la crisis de las teorías del desarrollo o del desarrollo mismo ha
generado un interesante debate al interior de las ciencias sociales, el cual tiene como centro de atención los determinantes reales del comportamiento económico de las sociedades. Esa controversia tiene el mérito de haber iniciado — con relativo éxito- la superación tradicional de los análisis fragmentados provenientes de las distintas disciplinas sociales, para hacer converger las preocupaciones de sociólogos, economistas, historiadores, filósofos políticos, antropólogos y politólogos en un lenguaje compartido en el cual se destaca la intención de regresar, por diferentes caminos, al concepto complejo de economía política, base de las teorías clásicas de Smith, Marx y Weber. Resulta evidente, entonces, que el aporte más significativo del debate tiene que ver con la recuperación de una mirada integral acerca de los procesos sociales, en la cual se enfatiza acerca de las interrelaciones de normas legales, sistemas de poder político, códigos de conducta, esquemas organizacionales y arreglos económicos a partir de los cuales se han estructurado, históricamente, las sociedades.

En ese marco, se considera que el programa de investigación de la llamada nueva economía institucional (NEI) ha asumido como propio el interés por revalorar el papel jugado por los factores institucionales y, con ello, el de replantear las complejas relaciones entre los procesos económicos, políticos y culturales que se entretejen en las sociedades humanas. Desde allí, esta perspectiva ha logrado permear el análisis político y sociológico y hoy alimenta las más recientes versiones acerca del desarrollo, a la vez que pretende convertirse en la herramienta conceptual, por excelencia, en la formulación de la política pública en los países atrasados.

Una revisión rápida de los últimos documentos producidos por organismos internacionales como el Programa de las Naciones Unidas para el Desarrollo (PNUD), el Banco Mundial (BM), la Comisión Económica para América Latina de las Naciones Unidas (CEPAL), el Banco Interamericano de Desarrollo (BID), lo mismo que de una gran cantidad de literatura académica, parece mostrar un acuerdo unánime respecto de la explicación que la NEI propone acerca de las causas del desarrollo y, consecuentemente, del atraso de países como los de América Latina. Parecería entonces que, al haber llegado al final del debate conceptual, nos encontráramos en el momento de pasar del plano explicativo al de la prescripción, para lo cual sería necesario diseñar un marco de políticas estatales y acciones privadas que le permitan a las naciones transitar hacia el desarrollo institucional $—$ o consolidar

\section{Desaarrollo}


el ya alcanzado - para resarcirse de lo que ha significado el fracaso evidente del proyecto de la modernidad. El título del informe del Banco Mundial de 1997 ("El consenso postWashington: las instituciones importan") hace alusión al advenimiento de dicho acuerdo, el cual, supuestamente, dejaría sin validez el famoso Consenso de Washington, en el que las naciones ricas del planeta decretaron, como único camino viable hacia el progreso, la muerte del estado benefactor keynesiano y la liberación de las fuerzas del mercado (Valdivieso, 1997).

Para las disciplinas sociales — que son, por definición, espacios de confrontación de referentes conceptuales - tiene que resultar inquietantes, e incluso sospechoso, todo tipo de consensos analíticos o programáticos, tanto los que tienen detrás el sello de la capital estadounidense, como aquellos que se postulan como contestatarios. El objetivo de este artículo consiste, entonces, en hacer un recorrido por el programa de la NEI hasta llegar a la teoría del desarrollo derivada del mismo y a su interpretación del atraso de América Latina, con el fin de mostrar no sólo los avances de esta nueva perspectiva respecto de sus predecesoras, sino también algunas de sus fisuras.

Con ese propósito, en la primera parte se plantearán las líneas teóricas que alimentan el programa de la NEI, enfatizando en la perspectiva del Nobel de Economía, D. North dado que es su visión de la evolución histórica de Occidente la que sirve de base a las propuestas actuales de los organismos multilaterales. Posteriormente, se reseñan algunas de las contribuciones más representativas de autores y organismos que, desde el marco neoinstiucional, han explicado las causas del subdesarrollo latinoamericano o han adelantado programas de superación del mismo para, finalmente, destacar algunas posibles limitaciones de este enfoque, el cual amenaza con convertirse en un dogma más, entre los tantos que han servido para que nuestros países se conciban a sí mismos y se proyecten hacia el futuro.

\section{El punto de partida}

Por qué algunos países se comportan mejor económicamente que otros, es la pregunta inicial en el trabajo de North. Cuáles procesos tienen lugar al principio de los tiempos modernos como para explicar la senda de crecimiento continuo de algunas regiones y el retraso relativo de otra parte del mundo, es la preocupación que está presente a lo largo del trabajo de ese autor institucionalista.

El tema, por supuesto, no es novedoso. Estuvo en la base de grandes teorías de la historia, como las de Adam Smith, Marx y Weber. Orientó las hipótesis explicativas de Schumpeter y Kutznets y es el hilo conductor de las muy modernas propuestas del desarrollo endógeno y el capital humano. Tampoco es nueva la referencia a la importancia de las instituciones, ya que el esquema de Smith no tiene sentido sin la presencia de estímulos al ahorro, a la división del trabajo y a los aumentos de la productividad. En el marxismo, los derechos de propiedad juegan un papel preponderante, lo mismo que en la versión

\section{DeSarrollo}


weberiana la ética protestante constituye el motor de crecimiento del capitalismo. Heredera, entonces, de esas macroteorías de la historia, la propuesta de North altera las relaciones entre cambios económico e institucional, además de introducir como herramientas analíticas dos conceptos claves para la nueva economía institucional: los costos de transacción (lo cual involucra una referencia clara a la economía de la información) y la lógica del accionar colectivo, confrontada con la racionalidad individual.

\section{Los conceptos básicos: instituciones y organizaciones}

"Las instituciones son las restricciones ideadas por los humanos que permiten estructurar los intercambios económicos, sociales y políticos", afirma North (1991:3) en un artículo destinado a delimitar los conceptos en los cuales se asienta su programa de historia institucional. Dichas restricciones pueden ser informales — costumbres, códigos tácitos de conducta, tradiciones, tabúes y convenciones-, o pueden estructurarse como reglas formales mediante las constituciones, leyes o derechos de propiedad. Los mecanismos que permiten regular o imponer tales normas también pueden ser considerados instituciones y, de hecho, juegan un papel significativo en este enfoque, ya que "el grado de identidad entre los objetivos de una pauta institucional y las elecciones individuales depende de la efectividad de los mecanismos de refuerzo, los cuales pueden provenir de una interiorización de las normas, de la sanción social o imposiciones coercitivas del Estado" (North, 1990:6).

Para North es claro que las instituciones surgen para reducir la incertidumbre presente en los procesos económicos, una vez que empiezan a adquirir algún grado de complejidad. Éstas existen por la limitación de los procesos humanos de computación frente al desarrollo de la información y por la existencia de costos de transacción en todos los ámbitos de la interacción humana. De la primera razón se desprende que la información de los agentes es siempre incompleta por lo que, en la mayoría de los casos, actúan en condiciones de incertidumbre, la cual disminuye con la implantación de reglas de juego claras. La presencia de instituciones como garantías, licencias, instituciones de arbitraje actúa, en el segundo caso, para disminuir costos de transacción.

Las reglas informales, en esta perspectiva, constituyen un conjunto fundamental de instituciones consistentes en convenciones comunes destinadas a resolver problemas de coordinación, o pueden ser, alternativamente, códigos de conducta autoimpuestos, tales como estándares de honestidad e integridad y normas de comportamiento que se refuerzan por la sanción social o la autoridad coercitiva. La habilidad de las instituciones para estimular el cambio y las actividades productivas y delimitar en forma satisfactoria los derechos de propiedad y los contratos o, por el contrario, para incentivar las actividades redistributivas es, de acuerdo con este autor, el más crucial determinante del comportamiento económico (North, 1993).

\section{DeSarrollo}


Si las instituciones son las reglas de juego, plantea nuestro autor, las organizaciones son los jugadores. Las últimas están compuestas por grupos de individuos con objetivos comunes y su calidad, lo mismo que sus rasgos, están determinados por las oportunidades definidas por el marco institucional vigente. Firmas, sindicatos, bancos centrales, son ejemplos de organizaciones económicas; cuerpos religiosos y clubes son ejemplos de organizaciones sociales. Las organizaciones buscarán adquirir los conocimientos y habilidades que le brinden mayores oportunidades frente a una matriz institucional definida, que es la que estructura los incentivos positivos — si estimulan la productividad - o negativos, si promueven el comportamiento oportunista o el engaño.

\section{Los referentes teóricos (1): tan cerca y tan lejos de la economía convencional}

En un artículo ${ }^{1}$ de 1993 North define las relaciones de su programa de investigación con la teoría neoclásica y plantea la concordancia de su pensamiento "con el postulado inicial de la escasez y de ahí, el de la competencia; ve la economía como una teoría de la elección de individuos sujetos a restricciones; emplea la teoría de los precios como una parte esencial del análisis de las instituciones y observa en el cambio en los precios relativos la mayor fuerza para inducir cambios en las instituciones" (1993). De la misma forma, rechaza la racionalidad instrumental que anula la importancia de las instituciones, elimina de los escenarios de análisis las ideas y las ideologías y conduce a pensar el mundo como un agregado de mercados eficientes. "En adición a la modificación al postulado de la racionalidad, añade las instituciones como elementos determinantes y analiza el rol de los costos de transacción y la conexión entre instituciones y costos de producción". ${ }^{2}$ La intención es incorporar las ideas y las ideologías en el análisis, modelando los procesos políticos como un factor crítico en el desempeño de las economías, causante del desigual comportamiento de éstas y de la existencia de mercados ineficientes.

Destaquemos las implicaciones que, según nuestro autor (North, 1994), se derivan de la negación del postulado de la racionalidad instrumental. El marco analítico de la elección racional asume que los individuos conocen todo lo que redunda en su beneficio personal y actúan de acuerdo con ello. La información completa y perfecta y la ausencia de fricciones caracterizan, entonces, el mundo neoclásico. Esto puede ser correcto, dice North, para individuos que realizan decisiones en pocos mercados de las modernas economías, pero es patentemente falso cuando las elecciones se hacen en condiciones de incertidumbre, la cual está presente en la mayoría de las decisiones económicas y políticas

1 La mejor colección de papers en Economía Institucional se encuentra en la página web de la Internationational Society for New Institutional Economics que, en adelante, se citará www.isnie.org. 2 Esto fue ratificado por North en su disertación con motivo de la entrega del premio Nobel de Economía (1994).

\section{DeSarrollo}


cruciales del mundo actual. En esas condiciones, los actores económicos y políticos tienen diferentes percepciones acerca del entorno, determinadas por el tipo de aprendizaje que adquieren con el tiempo, lo cual, a su vez, se enmarca en el complejo ambiente de los procesos culturales.

\section{Los referentes teóricos (2): costos de transacción y derechos de propiedad}

La NEI puede considerarse la intersección final de un buen número de diferentes líneas de investigación, incluidas las enfocadas al análisis de las normas de comportamiento, la formación de los grupos de interés, las limitaciones de la racionalidad en el comportamiento humano, el cambio tecnológico y su relación con el institucional, los problemas de coordinación, entre otros. ${ }^{3} \mathrm{Si}$ bien es cierto, entonces, que es una sombrilla amplia bajo la cual se pueden considerar gran variedad de enfoques o fragmentos de teorías, existen dos temas recurrentes en todas las vertientes, incluida la de North: los costos de transacción y los derechos de propiedad.

El concepto costos de transacción fue introducido por Coase (1960), quien sugirió que las firmas y otras instituciones existen porque hay límites en el uso de los mecanismos de mercado. Según ese autor, sólo cuando la información relevante para los intercambios es de conocimiento público, los costos de transacción son cero y, por lo tanto, la asignación de derechos de propiedad puede hacerse mediante procesos de negociación y conciliación, caso que únicamente se presenta en el mundo neoclásico, en el cual las personas conocen todo lo que redunda en su interés propio y actúan de acuerdo con ello. El trabajo de Oliver Williamson $(1989,1991,1996)$ estimuló esta orientación temática al combinar el análisis con los conceptos de racionalidad limitada o acotada y comportamiento oportunista, con los cuales analizó los problemas de la estructura interna de las organizaciones.

La hipótesis central de North es que las instituciones son arreglos de la sociedad destinados a la disminución de costos de transacción, los cuales fueron definidos por ese autor, originalmente, como costos de investigación y negociación, incluidos los de regulación e imposición de las normas (enforcement cost) (North, 1991); más tarde amplió el concepto al integrar los de medición y protección de los derechos de propiedad. Según esto, los costos de transacción incluyen el ensamblaje de la burocracia gubernamental, los de funcionamiento de los partidos políticos así como todo aquello que favorece los intercambios complejos como la banca, las finanzas, las aseguradoras. Para ilustrar su argumento, se refiere a la progresiva consolidación de los intercambios impersonales, que demandan procedimientos de ejecución de contratos cada vez más rigurosos.

3 Existen muchas obras dedicadas a reseñar los distintos orígenes de la problemática neoinstitucionalista: Langlois (1994), Hodgson (1988), Rutherford (1995), Drobak y Nye (1997) son algunas de las más completas. 
Desde sus obras pioneras, en las cuales, según sus propias palabras, "Thomas y yo hicimos de los derechos de propiedad el centro de nuestra explicación sobre el comportamiento económico" (North, 1991:4), el argumento de North se ha matizado de modo considerable, especialmente en dos sentidos. Primero, las normas de comportamiento informales condicionan, de manera crítica, la forma en la cual las instituciones influyen en el accionar económico; segundo, dado que los derechos de propiedad son especificados y regulados por medio de políticas, la evolución de éstas es lo único que puede dar pautas acerca de la trayectoria de esos derechos. Desde esa nueva perspectiva, se plantean múltiples interrelaciones de las autoridades políticas, las instancias judiciales y el mercado, las cuales confluyen en la definición de los derechos de propiedad. Es decir, la evolución de las instituciones no obedece a una simple lógica del mercado que propicia la aparición de arreglos institucionales cada vez más eficientes, sino que el entorno institucional presenta los incentivos; éstos son filtrados por medio de los esquemas mentales de los actores, quienes decidirán de acuerdo con su perspectiva de qué pueden representar mayores beneficios individuales u organizacionales.

\section{Los referentes teóricos (3): la lógica de la acción colectiva o el problema del viajero-sin-pasaje}

Aun cuando la teoría de la acción colectiva constituye una línea de análisis independiente dentro de la corriente neoinstitucionalista, North ha integrado en su marco analítico algunos de sus aspectos básicos, especialmente en la perspectiva de Olson y de Weinngast, su habitual colaborador. Esta teoría tiene que ver con los bienes públicos o colectivos, de carácter físico, como la polución o un parque, y con los bienes públicos intangibles, como una regulación o una regla política, los cuales, por supuesto, han resultado de mayor interés para las ciencias sociales (Olson, 1971).

La problemática respecto de los bienes públicos se relaciona con las dos características que le son inherentes, esto es, una vez que los bienes se proveen, ningún individuo puede ser excluido de su beneficio, y éste no disminuye, a pesar de que aumente el número de quienes lo reciben. Estos rasgos promueven la aparición, en el marco de las colectividades, de comportamientos no eficientes que, incluso, llevan a una provisión de bienes públicos por debajo de los niveles de necesidad social. La teoría ha estado interesada, no sólo en averiguar la forma de optimar el beneficio de los individuos, sino también en establecer las condiciones en las cuales los acuerdos entre distintos grupos de interés pueden ser logrados. Es precisamente aquí donde se enlaza con la interpretación northiana del cambio institucional, ya que se refiere al comportamiento de los grupos de presión, de las organizaciones económicas y políticas en relación estrecha con determinadas condiciones del entorno institucional. 
De la teoría de la acción colectiva, North ha tomado el concepto de que el Estado y sus agentes no son actores pasivos frente al proceso de interacción social. ${ }^{4}$ Por el contrario, es claro que los grupos de presión pueden utilizar las políticas públicas en beneficio propio, afectar los patrones de voto, utilizar las agencias reguladoras o legislativas, incidir en las decisiones judiciales, entre otros. De esa forma, se contribuye a enviar señales a la población acerca de los beneficios del comportamiento oportunista, generándose un conjunto de incentivos que desestimulan las actividades productivas a favor de los captores de renta. ${ }^{5}$

\section{El atraso de América Latina: un marco institucional} ineficiente e inestable

Como se sabe, los procesos de desarrollo del mundo occidental fueron el punto de referencia para los análisis de North $(1984,1986,1991)$. Su interpretación de las diferentes pautas históricas, seguidas por Inglaterra-Estados Unidos frente a España-Portugal, es lo que le ha permitido a ese autor concluir que el secreto de las divergentes historias está en el diferente entorno institucional históricamente desarrollado en uno y otro ámbitos. En el caso de España, se reitera la referencia a una monarquía centralizada, apoyada en una potente burocracia civil, militar y religiosa, con un parlamento inexistente o debilitado, sin poder judicial independiente y con un grado elevadísimo de interferencia en la economía, con la consecuente supeditación de ésta a los intereses del Estado.

Según North, las instituciones británicas se desarrollaron en claro contraste con el cuadro anteriormente descrito, lo cual produjo una historia económica (que se extendió a las colonias norteamericanas) caracterizada por un sistema político de frenos y contrapesos, de sometimiento del poder al derecho y una estructura básica de derechos de propiedad bien definidos. Esos factores incentivaron, en el largo plazo, el desarrollo de la contratación, la producción y el intercambio, es decir, la creación de mercados y el crecimiento económico. Un marco de libertad política y económica, garantizada por organizaciones políticas democráticas, completaría el cuadro institucional del mundo desarrollado.

De acuerdo con la interpretación neoinstitucional, gran parte del éxito alcanzado por las sociedades occidentales avanzadas se debe a su evolución hacia contextos institucionales que favorecen los cambios incrementales continuos, que incentivan mayor representatividad de los actores, la autonomía de sus dirigentes y la deliberación permanente sobre los nuevos equilibrios institucionales necesarios. Cuando estas instituciones facilitadoras no existen o cuando los líderes organizacionales disponen de escasa maniobra o libertad de negociación por su falta de legitimidad o credibilidad frente a sus representados, se reduce o desaparece la posibilidad de llegar a acuerdos de compromiso.

\footnotetext{
4 Ésa es la razón por la cual se considera que el neoinstitucionalismo puede convertirse en un referente propicio para la formulación de políticas públicas.

5 Interpretación de los traductores de North del concepto rent-seekings.
}

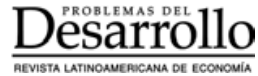


En la mirada a la evolución histórica de Occidente, North privilegia la idea de que en las sociedades se estructura una pauta de dependencia (path dependence), la cual se conserva con el tiempo y consolida ciertos marcos institucionales. Así, la historia reciente de los países latinoamericanos es una herencia de su pasado colonial y republicano:

La corona y sus burocracias — se expone en un documento del PNUD de 1998 - apoyadas por los detentadores de monopolios o patentes reales formaban la coalición que impidió el desarrollo, no solo del parlamento y de un derecho superior a la voluntad real, sino del incentivo necesario para la libre empresa, al no estar definidos legalmente ni asegurados judicialmente los derechos de propiedad ni el respeto de los contratos. En otras palabras, el fuerte intervensionismo económico y el poder arbitrario impidieron el surgimiento de una sociedad civil autónoma y potente, dejando permanentemente frustrada o pendiente la revolución liberal (Prats, 1998:3).

La historia latinoamericana ha perpetuado — según la NEI — la tradición centralizada y burocrática de su herencia hispano-portuguesa y, en consecuencia, ese marco institucional no permite el intercambio interpersonal y complejo propio de las sociedades modernas ni garantiza la estabilidad política requerida para capturar las ganancias económicas potenciales derivadas de la tecnología moderna.

Es posible observar en la literatura más reciente un esfuerzo, tal como plantea Haber, por "emplear la historia de las economías latinoamericanas como un laboratorio para la investigación empírica del Nuevo Institucionalismo" (2000:9). Cuatro textos, publicados en 1997, 1998, 2000 y 2001, respectivamente, pueden considerarse representativos de la versión neoinstitucional de la historia de América Latina y serán los que se tomen como referencia en este apartado. En el primero de ellos, el cual tiene como trasfondo la experiencia de Brasil y México, Haber (1997) se pregunta por los factores explicativos para que en América Latina se originaran "tradiciones legales y políticas poco propicias para la transformación estructural y el reparto amplio de las ganancias del crecimiento". El segundo, un documento de trabajo del PNUD, además de insistir en el origen institucional del atraso latinoamericano, adelanta algunas propuestas para que la región renueve su pauta de desarrollo institucional y propicie las reformas necesarias para el cambio (Prats, 1998). El tercero, una colección de ensayos también editada por Haber (2000), presenta una serie de estudios de caso en los cuales, a partir del análisis de aspectos puntuales de la evolución económica de nuestros países o de la política pública implantada, se pretende probar el peso específico de los aspectos institucionales en la historia del subcontinente. En el cuarto de los textos mencionados, Kalmanovitz (2001) expresa una visión panorámica en cuanto a la falta de legitimidad de las políticas estatales, el impacto negativo de la ideología religiosa de corte católico, el origen del clientelismo y diversas formas de corrupción, para concluir que los arreglos institucionales de la sociedad colombiana "han impedido [...] una acumulación suficiente de capital y han fallado en proveer 
la seguridad legal, los incentivos económicos y las formas de participación social requeridas para un desarrollo económico sostenible y equitativo y para el logro de una sociedad capaz de enfrentar democráticamente sus conflictos internos". Los cuatro coinciden en destacar la ausencia en esta zona de una definición precisa de los derechos de propiedad y de instituciones democráticas y, como consecuencia de ello, la carencia de procesos conducentes a la construcción de una sociedad civil propositiva y con algún margen de poder a la hora de tomar decisiones.

\section{Marcos institucionales y crecimiento económico}

Como ya se mencionó, la línea de análisis abierta por la NEI ha concentrado su interés en los efectos que diferentes sistemas políticos e institucionales, así como su nivel de estabilidad, tienen en el comportamiento económico, en la mayoría de los casos concebido como sinónimo de crecimiento económico, medido por el PIB. El motor del crecimiento es, según esta perspectiva, la estructura institucional y organizacional y sus repercusiones en el conjunto de incentivos, no sólo para innovar, sino para organizar los procesos productivos más eficientemente, reducir los costos de transacción en los mercados de factores y productos y organizar un sistema judicial capaz de hacer cumplir los contratos, generar reglas políticas que especifiquen los derechos de propiedad y — lo más importante de todo- mantengan con el tiempo esos incentivos positivos.

Interesa destacar que, según la NEI, en aquellas sociedades que logren establecer un marco institucional eficiente se generarán externalidades positivas y bienes públicos que afectarán favorablemente a toda la población, impidiendo el oportunismo de los captores de renta. Por el contrario, la inestabilidad y la baja calidad institucional no sólo disminuyen el nivel de eficiencia social, al reducir las posibilidades de producción e intercambio, sino que, igualmente, distorsionan los patrones culturales y de expectativas de la comunidad.

Con base en las proposiciones teóricas de la NEI arriba mencionadas, en los últimos años se ha realizado una serie de estudios empíricos que establecen relaciones de causalidad entre distintos factores institucionales y el crecimiento económico en una serie de países. ${ }^{6}$ Para los propósitos de este escrito, se pueden identificar en los estudios mencionados tres mecanismos por medio de los cuales el entorno institucional impacta los niveles de crecimiento y de bienestar de las sociedades. El primero de ellos, el cual ha recibido más atención en la literatura neoinstitucionalista, es el efecto que las condiciones institucionales tienen en la inversión privada. Es evidente que la inestabilidad política e institucional desestimula la acumulación de capital, dado que aumenta el nivel de riesgo y la incertidumbre en los retornos futuros de las inversiones. Un segundo elemento que se propone para observar la relación entre factores institucionales y crecimiento, según los estudios

${ }_{6}$ Algunos de los estudios que han tenido más impacto son: Knack y Keefer (1995), Barro (1997) y los contenidos en el volumen editado por el propio North, junto a Alston y Eggertsson (1996).

\section{Desaarrollo}


empíricos aludidos, tiene que ver con la formación de capital humano: la incertidumbre institucional y la posibilidad de obtener mayores retornos en las actividades clientelistas — o, incluso, mediante la corrupción administrativa — reducen la inversión en educación $\mathrm{y}$, con ello, las posibilidades de aumentos de productividad. Por último, los análisis enfatizan en el peso relativo que tienen los contextos institucionales en los sistemas normativos y la estructura de valores de la población: el deterioro institucional, según su perspectiva, puede estimular el comportamiento oportunista de los individuos, al resultarles más rentable involucrarse en actividades por fuera de la ley que participar en actividades productivas dentro de los cánones de la normatividad social.

El Banco Mundial - al recoger las conclusiones de esos estudios y tomar como indicadores de desarrollo institucional la seguridad en las inversiones, la claridad en la asignación de derechos de propiedad, la garantía en el cumplimiento de los contratos, la existencia y confiabilidad de los mecanismos de solución de disputas y los niveles de corrupción existentes- ha mostrado también una correlación positiva entre un buen marco institucional y el crecimiento económico. ${ }^{7}$ Esta nueva visión tiene el mérito de adoptar una explicación menos simplista de los determinantes del crecimiento que aquella que lo vinculaba directamente a la ciencia, la tecnología y la acumulación de capital y, además, el de reconocer las especificidades de los territorios en lo relacionado con la herencia histórica de normas culturales que rigen la vida en sociedad.

La emergencia del proyecto de investigación de la NEI se ha dado de manera paralela con las intensas transformaciones tecnológicas, económicas y políticas que marcaron el fin del siglo pasado. En ese escenario, son evidentes las fisuras de las propuestas convencionales del desarrollo cuya herencia se manifiesta en una serie de profundas paradojas (Valdivieso, 1995). De una parte, los avances tecnológicos hacen pensar en la posibilidad del dominio del hombre sobre la naturaleza, el cual se derivó de la confianza ilimitada de la ciencia como promotora de progreso pero, a la vez, manifiestan en toda su crudeza y magnitud los desequilibrios ecológicos y el escaso margen de acción de las políticas correctivas en ese campo. Igualmente, mientras las capacidades productivas de la humanidad parecen multiplicarse a un ritmo tal que se desecha cualquier crisis alimentaria en términos absolutos, las cifras muestran una tremenda desigualdad en la distribución de los recursos, lo cual hace que un tercio de la población mundial no tenga satisfecha sus necesidades de supervivencia. Por último, en la mayoría de los países de América Latina se han seguido las recetas y recomendaciones de organismos internacionales como la liberalización, la estabilización y la privatización - premisas centrales del Consenso de Washington- sin que haya llegado el crecimiento esperado, provocando, en cambio, una profundización de la crisis social endémica que ha vivido el continente.

7 Véanse Banco Mundial (2001) y Prats (1998).

\section{DeSarrollo}


Ese ambiente de crisis social y teórica ha resultado propicio para introducir el análisis institucional en la teoría del desarrollo. Así, es de la mano de esta propuesta que se traslada el énfasis explicativo acerca de las causas del atraso, de la carencia de capital financiero, de inversión o capital humano, hacia los marcos institucionales inestables o ineficientes e incapaces de promover las actividades productivas y rentables. Desde diferentes perspectivas, se proclama la necesidad de revisar la relación dinámica entre el desempeño económico y variables tradicionalmente marginadas del análisis, como la política, los sistemas de justicia, las normas de conducta, la existencia de redes sociales de cooperación, elementos que forman parte del bagaje conceptual del neoinstitucionalismo.

\section{Desarrollo institucional y capital social}

Al eclipsarse el papel del Estado en medio de la crisis de los ochenta, se le confió a la teoría neoclásica las propuestas para superarla: como el problema se había originado, según esta perspectiva analítica, en una intervención excesiva del aparato estatal que desalentaba la actividad privada, el mercado debía recibir nuevamente un papel protagónico, acompañado por un paquete de medidas que apuntaban a la estabilización monetaria, el ajuste fiscal y la liberalización de las economías. El llamado Consenso de Washington expresa el compromiso internacional con esas medidas, orientadas a corregir los desequilibrios macroeconómicos de las economías, como presupuesto del crecimiento. Sin embargo, su capacidad para incidir en la producción, por sí solas, pronto se revela insuficiente (Stiglitz, 2002). Según un representante del BID,

los economistas neoclásicos asumieron como dadas ciertas condiciones que suelen estar ausentes en los países en desarrollo: un sistema jurídico que ampare la seguridad de los derechos de propiedad, dispositivos regulatorios que eviten el fraude y la restricción de la competencia, mecanismos fiables de resolución de conflicto, una sociedad mínimamente cohesionada en torno a valores de cooperación, instituciones políticas que amortigüen tensiones sociales y un Estado limitado y controlado por contrapesos entre sus diversos poderes (Echebarria, 2001:4).

La constatación de la inexistencia de una competencia perfecta en la que actúen los mecanismos de mercado para garantizar situaciones de equilibrio y la peligrosa profundización de la crisis social en los países que habían aplicado la receta salvadora del ajuste estructural se convirtieron, así, en el mejor caldo de cultivo para la renovación de los conceptos convencionales del desarrollo y para la introducción en la agenda del desarrollo de las llamadas reformas de segunda generación, derivadas de la necesidad de robustecer las instituciones para alcanzar las metas del bienestar. De esa manera, se introdujeron en el análisis, de una parte, las temáticas neoinstitucionales mediante la prioridad dada al desarrollo institucional y al nuevo concepto de capital social y, de otra, la perspectiva del desarrollo como incremento de las capacidades y libertades humanas, cuyo representante 
intelectual más notable es A. Sen, por medio de su complementario, el desarrollo humano. Ambas corrientes de pensamiento coinciden en destacar la importancia de las instituciones para el desarrollo, aun a pesar de que el significado y el alcance que atribuyen a la institucionalidad es muy diferente. Nos interesa detenernos fundamentalmente en la primera de estas nuevas versiones del desarrollo, dado que es la que se relaciona más directamente con la NEI.

La perspectiva propiamente económica del neoinstitucionalismo se ha entrecruzado en los años recientes con los análisis sociológicos acerca del papel de las redes sociales de cooperación y los sentimientos de confianza para estructurar intercambios positivos en la comunidad y desarrollar marcos institucionales eficientes, lo cual ha dado como resultado el paradigma emergente del capital social (Putnam, 1993). La referencia a los orígenes del concepto, a la ambigüedad en su tratamiento por parte de algunos organismos internacionales o por diseñadores de políticas públicas, y a las dificultades de establecer referentes empíricos para medirlo, se sale de los límites de este artículo, pero resulta interesante anotar los factores que enfatiza Putnam, precursor de esta línea de análisis, para explicar las diferencias entre el norte industrializado y el sur rezagado de Italia: el grado de confianza entre los actores sociales, las normas de comportamiento cívico practicadas y el nivel de asociatividad que los caracteriza. Según nuestro autor, esos factores son reflejo de la riqueza y fortaleza del tejido social y contribuyen, de manera decidida, al buen funcionamiento de la sociedad.

Pese a las diferencias en el tratamiento del término capital social, la mayoría de los estudios coinciden en señalarlo como ese nexo que une a las sociedades y sin el cual no puede haber crecimiento ni bienestar humano: actúa positivamente al facilitar la transmisión de conocimiento sobre la tecnología y los mercados y la toma de decisiones colectivas, reducir el problema del oportunismo y fomentar la coordinación de actividades, en otras palabras, es un factor generador de matrices institucionales eficientes.

Trasladado este análisis al ámbito de nuestros países, se concluye que, si la enfermedad de América Latina es su debilidad institucional (Prats, 1998) o, dicho de otra manera, si el mayor problema es que no hemos hecho una revolución liberal (Kalmanovitz, 2001), la verdadera cuestión —en el marco de la teoría y la práctica del desarrollo- consiste en indagar, desde el conocimiento de la propia pauta de dependencia institucional y desde los propios parámetros valorativos nacionales, cómo hacer evolucionar las instituciones existentes hacia sistemas renovados que incentiven la eficiencia económica y la equidad social. La respuesta a esa interrogante es obvia: se necesita configurar una sociedad civil deliberante y actuante, un sistema electoral que permita ampliar los espacios democráticos, modernizar los sistemas judiciales y tributarios, fortalecer el poder legislativo y los organismos reguladores, generar redes de cooperación y participación ciudadana, esto es, construir capital social.

\section{DeSarrollo}


Es necesario destacar algunos elementos positivos en esta renovada concepción del desarrollo. El primero, si bien no existe esa confianza sin reservas en el Estado — que marcó el periodo keynesiano de la posguerra - como generador de desarrollo, se pone fin a la vieja interpretación excluyente de la acción del Estado vs. el mercado, para dar paso a una apreciación más matizada acerca de las funciones compartidas de las dos instituciones, que participa con la sociedad civil en la definición de los procesos sociales.

Pero ha sido, sin duda, la valoración de algunos temas relevantes para acercarse a la compleja realidad de nuestra región, la herencia más concreta de esta perspectiva analítica, que ha abierto, como se planteó en la introducción de este documento, un campo amplio de debate en cuanto a la eficiencia de los sistemas de representación, la legitimidad de las acciones gubernamentales, el alcance y la profundidad de las reglas democráticas, los vicios burocráticos, el clientelismo y la corrupción, por mencionar algunos. Por supuesto, es imposible estar en desacuerdo con la necesidad de "un nuevo Estado, bien podado y fuerte, capaz de suministrar los bienes y servicios que el mercado no alcanza a proveer eficientemente, respetuoso del orden constitucional y de las leyes, integrante de un poder judicial independiente y eficaz, capaz de combatir el poder arbitrario y su corolario, la corrupción" (Prats, 1998:25).

Sin embargo, la hipótesis que pretende esbozarse a continuación es que el programa de investigación de la NEI se ha trasladado del ámbito conceptual en el cual nació a otros que le son completamente extraños; por esa razón, sus explicaciones no pueden dar cuenta de la compleja problemática de la región latinoamericana y, en consecuencia, cuando pretende convertirse en programa de desarrollo o en mecanismos de política pública, puede mitigar algunas de las manifestaciones de esa problemática pero no impacta, en absoluto, sus verdaderas raíces.

\section{La NEI es Un subprograma de la corriente neoclásica}

De acuerdo con Alston et al. (1990:17), uno de los representantes más connotados de la versión neoinstitucional, el origen de esta vertiente se encuentra en el interés de "un buen número de economistas neoclásicos [que] comenzó a interesarse por la estructura de la organización económica buscando generalizar la teoría neoclásica mediante la modificación del cinturón protector [a partir de] la incorporación de los costes de información y de transacción y de las restricciones de los derechos de propiedad". A partir de este razonamiento, puede caracterizarse a la NEI como una extensión de la ortodoxia económica. Este autor hace explícita su intención de dejar intacta la base conceptual neoclásica: "mi regla de funcionamiento - afirma - era limitar el estudio a contribuciones que no alteraran el núcleo del enfoque económico, particularmente el modelo de elección racional, y buscar una nueva síntesis entre la economía neoclásica e institucional”. En la misma línea de pensamiento, North, en su disertación al recibir el premio Nobel, no deja lugar para las 
dudas: "El marco analítico es una modificación de la teoría neoclásica. Lo que se retiene es el supuesto fundamental de la escasez y, con ello, de la competencia y las herramientas analíticas de la teoría microeconómica. Lo que se modifica es el postulado de la racionalidad. Se añade la dimensión del tiempo" (1994:359). ${ }^{8}$

Los únicos dos elementos novedosos, entonces, tienen que ver, de una parte, con el reconocimiento de que en los mercados no existe información completa y perfecta y que, por lo tanto, el homus economicus no siempre puede tomar decisiones racionales. Con esto, la NEI relaja el supuesto neoclásico y acepta la noción de racionalidad limitada, según la cual existen múltiples restricciones a la conducta plenamente racional de los sujetos. Por otra parte, se introduce la perspectiva histórica en el análisis. Ninguno de los dos factores significa una ruptura con el núcleo duro de la teoría neoclásica, sino que ambos se ubican en ese cinturón protector cuyos cambios complementan o adecuan el cuerpo teórico original.

Ahora bien, la caracterización de la NEI como neoclásica no tiene una intención peyorativa o de descalificación a priori, sólo pretende destacar el alcance real de esta pretendida renovación conceptual, la cual podría reducirse, a mi juicio, en la eliminación de la competencia perfecta que está en la base de los análisis neoclásicos tradicionales, para reconocer las fallas del mercado y los costos de transacción derivados. En su obra fundamental, North (1993) sostiene que los mercados eficientes son bastante escasos en lo económico e incluso más en el mundo político. Para la NEI, las instituciones - económicas y políticas - surgen, precisamente, como un mecanismo social orientado a mejorar los resultados del mercado, aun cuando, en ocasiones, terminen por generar el efecto contrario.

Para continuar en esta misma línea de análisis, si actúa en la periferia del paradigma neoclásico, ${ }^{9}$ la NEI sólo puede ser una corriente explicativa del diferente comportamiento de los mercados con el paso del tiempo y, como tal, puede ubicarse en el espacio de las teorías del crecimiento económico. De hecho, los costos de transacción y los derechos de propiedad son categorías propias de las economías de mercado, en las cuales los agentes propietarios intercambian bienes y servicios para optimar su utilidad o sus beneficios. La NEI justifica la intervención del Estado cuando se trata de garantizar que esa economía de mercado funcione y, en esa medida, esta perspectiva reduce el papel del poder político y de los arreglos institucionales de todo tipo a las funciones económicas de disminuir la incertidumbre y proporcionar la estabilidad legal necesaria para las inversiones de largo

8 Traducción libre de la autora del presente artículo. Las cursivas son nuestras, así como en las citas posteriores.

9 Algunos autores han intentado ver en la NEI una superación del individualismo metodológico en el cual se basa este paradigma. Sin embargo, su enfoque sigue siendo, en esencia, individualista: las instituciones surgen mediante la interacción de individuos y no de grupos, aun a pesar de que se hable de la acción colectiva. 
plazo (Burgos, 2002). Es esta una limitante importante a la hora de postular explicaciones sensatas de la realidad latinoamericana, ya que en nuestros países es posible constatar el papel regresivo del Estado y su evidente sesgo político a favor de segmentos de población reducidos y privilegiados.

Para que la anterior afirmación no parezca demasiado descontextualizada, es posible citar, entre comillas, las justificaciones que autores u organismos — que utilizan como referente los postulados neoinstitucionales - dan acerca de la necesidad del cambio institucional. Así, el PNUD escribe que éste se hace necesario "para construir progresivamente las llamadas instituciones del capitalismo de mercado como el derecho a la competencia, el mercado de valores, la supervisión de la banca, la reestructuración del mercado de trabajo" (Prats, 1998:24). Otro autor neoinstitucionalista plantea que: "El debate se centra en cuáles deben ser los arreglos institucionales, las reglas de juego, las normas explícitas e implícitas y el marco jurídico que permitan que las bondades del mercado se logren de manera cabal, que las fallas del mismo se mitiguen” (Roemer, 2002:1).

\section{Algunas consideraciones acerca del desarrollo en la perspectiva de la NEI}

Según datos de 2002, 20\% más rico de la población concentra 83\% de la riqueza mundial, en tanto que $80 \%$ más pobre (5 000 millones de habitantes de África, América Latina, Asia y Europa Oriental) recibe únicamente 17\% de la riqueza producida (PNUD, 2002). En el informe del Banco Mundial de 1997, dedicado al tema, se insiste en el carácter multidimensional de la pobreza y de la exclusión contemporáneas, los cuales no se reducen a la ausencia de ingresos económicos o a las dificultades para cubrir las necesidades mínimas de supervivencia, sino que se extienden a otras dimensiones de la vida humana y se reflejan en la exclusión de la vida pública y la nula participación en las decisiones sociales, en las barreras para el acceso a la educación y el desconocimiento de los valores culturales, entre otros. Más recientemente, el mismo organismo admite, igualmente, que la pobreza es, más que desarrollo humano inadecuado, vulnerabilidad y falta de voz, poder y representación (Bм, 2001).

Ante este panorama - del que hemos excluido los efectos perversos del modelo de crecimiento adoptado por el mundo occidental sobre el equilibrio ecológico y los recursos naturales - no deja de sorprender el carácter simplista de los encadenamientos causales establecidos por la explicación neoinstitucionalista del atraso. En uno de los documentos del PNUD que hemos citado anteriormente, se plantea si " ¿Tiene algo que ver el marco institucional con la equidad social?" y la respuesta es rotunda: "tanto o más que con la eficiencia económica" (Prats, 1998:25). Para sustentar esta respuesta, se pone de presente la tremenda desigualdad en las sociedades latinoamericanas y se procede a explicar las causas: 
el grueso de la pobreza latinoamericana procede de la dualidad estructural de sus sociedades [...] El dualismo —y la exclusión de los pobres que supone — proceden de un sistema institucional económicamente ineficiente fruto de la captura del poder político por una coalición social, que no permite la entrada de los pobres en el mercado de intercambios (ibid:26).

La raíz del problema se encuentra, según el documento que estamos reseñando, en el ámbito de la política, en la escasa profundidad de los esquemas democráticos y en la estrechez de los mercados económicos, coincidiendo aquí con Kalmanovitz, cuando plantea que el origen de la situación colombiana es la ausencia de una verdadera revolución democrática. El análisis es unidireccional y sesgado, dado que se asume como variable independiente el marco institucional ineficiente y su corolario, la dualidad social, cuando existe un cúmulo de evidencias e investigaciones que permiten considerar esos fenómenos como el resultado de un proceso histórico de concentración de la propiedad —agraria e industrial — que ha condenado a buena parte de la población de los países latinoamericanos a la informalidad y a la búsqueda de mecanismos de supervivencia en prácticas por fuera de la ley o en la búsqueda de las migajas que el clientelismo y la corrupción les reservan para reproducirse.

Si es simplista la explicación del subdesarrollo, las propuestas para superarlo lo son mucho más. En primer lugar, la meta óptima de la sociedad, según la NEI y los organismos internacionales del desarrollo, es la economía de mercado y la democracia liberal, en una réplica exacta del sueño de Fukuyama, cuando pronosticó el fin de la historia. Independientemente de si se está de acuerdo con esa premisa, lo que puede observarse como resultado de los profundos cambios en la estructura económica mundial y en la relación de fuerzas geopolíticas de los últimos tiempos es la mundialización de los procesos de concentración económica y política y la profundización de la brecha entre países ricos y pobres y entre regiones al interior de los países. Esos fenómenos han provocado la extensión, en dimensiones insospechadas, de la precarización del trabajo, la exclusión de masas enormes de personas de los mercados formales y la multiplicación de formas de marginalidad relacionadas con aspectos culturales y religiosos, de género, de preferencias sexuales, de raza, de nacionalidad, lo cual hace parecer cada vez más lejano el sueño de la sociedad liberal.

Así las cosas, la propuesta de construcción de una institucionalidad democrática, de una sociedad incluyente basada en la participación, de redes de cooperación sustentadas en la confianza, de un sistema político transparente e igualmente incluyente y de un sistema judicial aislado de las redes de poder económico y político, no deja de ser más que un discurso, ${ }^{10}$ si se concibe dentro del marco de un modelo de desarrollo basado en la lógica

10 Alrededor del poder del discurso sobre el desarrollo se ha planteado recientemente en América Latina un interesante debate que las ciencias sociales tienen que registrar con satisfacción (Escobar, 1996).

\section{DeSarrollo}


del mercado, percibido como eficiente redistribuidor. Mientras persista la profunda brecha en los niveles de ingreso, se siga multiplicando la cantidad de pobres absolutos y relativos y el proceso de mundialización de la acumulación capitalista continúe potenciando nuevas formas de exclusión social y de marginalidad económica, política o social, la pretendida construcción de capital social sólo puede entenderse como una alternativa para acallar las voces de los inconformes. Es necesario, entonces, superar el concepto trivial de imperfecciones del mercado — susceptibles de superar con reformas institucionales_-para volver a concebir la problemática de los países de América Latina desde la perspectiva más compleja de las condiciones estructurales de la sociedad.

\section{Conclusión: la responsabilidad de las ciencias sociales}

En un artículo reciente, Joan Prats (2000:2) — director del Instituto Internacional de Gobernabilidad, asesor del PNUD y a quien hemos citado en extenso en este documentose lamenta de lo que considera una profunda crisis intelectual y moral en América Latina. "Apenas se atisban — dice - proyectos de sociedad distintos a las propuestas de los organismos internacionales - $-\mathrm{y}$ especialmente los bancos de desarrollo- convertidos, creo que sin pretenderlo, en los intelectuales orgánicos de la región. Y, lo que es peor, las anomalías a esta regla asemejan esperpentos construidos con remedos de la peor tradición populista".

Sin ser tan pesimista como Prats, es preciso considerar que este escenario de relativo repliegue de las ciencias sociales latinoamericanas está reflejando el enorme poder que el discurso convencional del desarrollo - ahora remozado con los calificativos de humano, sostenible e institucional y valorado como proyecto conjunto de los estados, la sociedad civil y los organismos internacionales-, tiene sobre la percepción que hemos desarrollado los latinoamericanos de nuestra propia realidad (Escobar, 1996).

La propuesta de la NEI ha servido como territorio — aparentemente neutral - en el que convergen pensadores conversos de las explicaciones estructuralista y dependentista de la problemática regional. En la medida en que se postula a sí misma como renovadora del pensamiento convencional y enfila baterías contra los vicios reales de nuestras sociedades, ha terminado por encontrar adeptos entre todos aquellos sectores que se resisten al escepticismo. El paso siguiente puede ser, como ha sucedido con la mayoría de las corrientes teóricas en economía, atribuir a las explicaciones neoinstitucionalistas el carácter de validez universal en lugar de entenderlas como hipótesis interpretativas conjeturales destinadas a ser siempre interrogadas y confrontadas en el desarrollo de procesos investigativos permanentes.

En ese marco, la responsabilidad de la comunidad académica consiste en negarse a dar por terminado el debate y proponer, en cambio, nuevas líneas de análisis, nuevos esque-

\section{DeSarrollo}


mas interpretativos y perspectivas metodológicas renovadoras que se enfrenten con fuerza argumentativa a cualquiera de las certezas adquiridas. Citando a Edgar Morin, "como en tantas otras épocas de la historia humana, a los espíritus sensibles sólo les queda una opción: resistir, explorar, inventar".

Bibliografía

Alston, L.; J. Eggertsson y D. North, Empirical Studies in Institutional Change, Cambridge, Cambridge University Press, 1996.

Atria, R. et al., Capital social y reducción de la pobreza en América Latina y el Caribe: en busca de un nuevo paradigma, Santiago de Chile, CEPALMichigan State University, 2003.

Ayala, J., Instituciones y economía, una introducción al neoinstitucionalismo económico, México, FCE, 1999.

Banco Mundial, Beyond the Washington Consensus: Instituttions Matter, Banco Mundial, 2001.

Barro, R., "Economic Growth in Cross Section of Countries", en Quaterly Journal of Economics, vol. 10, núm. 2, 1991, pp. 407-443.

Burgos, G., "Derecho y desarrollo económico: de la teoría de la modernización a la Nueva Economía Institucional", en Economía Institucional, vol. 4, núm. 7, segundo semestre, Bogotá, U. Externado de Colombia, 2002.

Coase, R., "The Problem of Social Cost", en Journal of Law and Economics, núm. 3, octubre de 1960.

, La empresa, el mercado y la ley, Madrid, Alianza Editorial, 1991.

Echebarria, K., Instituciones, reforma del Estado y desarrollo: de la teoría a la práctica, BID, 2001.

Eggertsson, Thráinn, El comportamiento económico y las instituciones, Madrid, Alianza, 1995.

Escobar, A., La invención del Tercer Mundo: construcción y deconstrucción del desarrollo, Bogotá, Norma, 1996.

Furubotn, E.G. y R. Richter, Institutions and Economic Theory: the Contribution of the New Institucional Economics, Detroit, The University of Michigan Press, 2000.

Haber, S. (editor), How Latin America Fell Behin: Essays on the Economic Histories of Brazil and Mexico, 1800-1914, Stanford, Stanford University Press, 1997. (editor), Political Institutions and Economic Growth in Latin America, Essays in Policy, History and Political Economic, Stanford, Hoover Institution Press, Stanford University, 2000 .
Hodgson, G.M., Economic and Institutions: A Manifesto for Modern Institutional Economics, Filadelfia, University of Pennsylvania Press, 1988.

Kalmanovitz, S., Las instituciones y el desarrollo económico en Colombia, Bogotá, Norma, 2001.

Knack, S. y P. Keefer, "Institutions and Economic Performance: Cross Countries Using Alternative Institutional Measures", en Economics and Politics, vol. 7, núm. 3, 1995, pp. 207-227.

Langlois, R.N., Economics as a Process: Essays in the New Institucional Economics, Cambridge, Cambridge University Press, 1986.

Nabli, M.K. y J.B. Nugent (editores), The New Institucional Economic and Development: Theory and Aplications to Tunisia, Ámsterdam, Elsevier Science Publishers, 1989.

North D., "Structure and performance: the task of Economic History", en Journal of Economic Literature, núm. 16, septiembre de 1978.

- Structure and Change in Economic History, Nueva York, W.W. Norton, 1981.

-, The Economic Growth of the United States, Nueva York, W.W. Norton, 1986.

_- Institutional Change: a FrameWork of Analysis, www.isnie.org, 1990.

, "Institutions", en Journal of Economic Perspectives, vol. 52, núm. 1, 1991.

, "Institutions and Economic Performance", en U. Maki (editor), Rationality, Institutions and Economic Methodology, Londres, Routledge, 1993.

, "Economic Performance Through Time", en American Economic Review, núm. 84, junio, 1994. -, Instituciones, cambio institucional y desempeño económico, México, FCE, 1995.

North, D. y Thomas, El nacimiento del mundo occidental: una nueva historia económica, Madrid, Siglo XXI, 1991.

Olson, M., The Logic of Collective Action-Public Goods and Theory of Groups, Harvard, Harvard University Press, 1971.

PNUD, Informe Annual 2001, www.undp.org/spanish, 2002.

Prats, J. y D.C. North, La teoría económica neoinstitucionalista y el desarrollo latinoamericano, 
documento de trabajo PNUD, Barcelona, Instituto Internacional de Gobernabilidad, 1998.

Prats, J., Instituciones y desarrollo en América Latina ¿Un rol para la ética?, documento del Instituto Internacional de Gobernabilidad, www.iigov.org, 2000.

Putnam, R., Making democracy work: civil traditions in modern Italy, Princenton, Princenton University Press, 1993.

Roemer, A., "El nuevo institucionalismo económico: herramienta de política pública", en Mercado de Valores, año 59, núm. 10, octubre, 1999, pp. 27-34.

Rutherford, Malcom, Institutions in Economics: the Old and the New Institutionalism, Harvard, Cambridge University Press, 1999.

Stiglitz, J., El malestar de la globalización, Madrid, Santillana, 2002.

Solimano, A., "Governance Crisis and the Andean Region: a Political Economy Analysis", CEPAL, www.eclac.org, 2002.
Valdivieso, S., "Reinventar el desarrollo", en Revista UIS-Humanidades, vol. 24, núm. 1, Bucaramanga, Universidad Industrial de Santander, 1995. , “Cuál es el costo del Consenso de Washington?", en Revista UIS-Humanidades, núm. 2, julio-diciembre de 1997.

, "North y el cambio histórico: luces y sombras de la nueva historia institucional", en Revista de Economía Institucional, núm. 4, primer semestre, Bogotá, Universidad Externado de Colombia, 2001.

Williamson, O., Las instituciones económicas del capitalismo: empresas, mercados y contratos relacionales, México, FCE, 1989.

-, Mercados y jerarquías: su análisis y sus implicaciones antitrust, México, FCE, 1991.

, The Mechanisms of Governance, Nueva York, Oxford University Press, 1996.

\section{DeSarrollo}

